\title{
ALUNOS SURDOS DOS ANOS INICIAIS DO ENSINO FUNDAMENTAL E A CONSTRUÇÃO DO NÚMERO
}

\author{
DEAF STUDENTS IN EARLY GRADE OF ELEMENTARY SCHOOL \\ AND THE DE ACQUISITION OF THE NUMERICAL CONCEPTS
}

\author{
Rosiane da Silva Rodrigues ${ }^{1}$ \\ Marlise Geller ${ }^{2}$
}

\begin{abstract}
Resumo
Este artigo analisa resultados de uma pesquisa de Mestrado sobre o ensino de conceitos numéricos iniciais com alunos surdos nos dois primeiros anos do Ensino Fundamental, em uma unidade especializada na educação de surdos. Por meio de uma abordagem qualitativa, constituíram-se reflexões sobre a importância do ensino ser pautado na língua de sinais e nas características pertinentes ao aluno surdo. O software Jclic configurou-se em uma ferramenta de auxílio à elaboração e aplicação de atividades, contribuindo para a aquisição dos conceitos numéricos e proporcionando opções de ludicidade e recursos para uma abordagem bilíngue, o que envolveu de maneira significativa os alunos na realização das tarefas.
\end{abstract}

Palavras-chave: Educação Matemática para Surdos. Anos Iniciais do Ensino Fundamental. Conceitos Numéricos Iniciais.

\begin{abstract}
This article analyzes results of a search about teaching Mathematics to a group of deaf students in their first two grades of elementary school in an institution specialized in deaf education. Through a qualitive approach, represent reflections on the importance of teaching be based on sign language and the caracteristic pertinent to the deaf student. The software JClic constituted in a useful tool for developing and implementing activities that contribute to the acquisition of the numerical concepts, providing options and resources for a playfulness bilingual approach, which involved significantly the students in the realization of activities.
\end{abstract}

Keywords: Mathematics for deaf education. Early grade students. Elementary school. Numerical concepts.

\footnotetext{
${ }^{1}$ Mestre em Ensino de Ciências e Matemática pela Universidade Luterana do Brasil (2002). Atualmente é professora de matemática da Fundação Escola Técnica Liberato Salzano Vieira da Cunha, em Novo Hamburgo e da APADA - Associação de Pais e Amigos dos Deficientes Auditivos de Sapiranga. Tem experiência na área de Educação com ênfase em Educação Matemática, principalmente em Educação Especial. E-mail: rosi.profe@bol.com.br

${ }^{2}$ Mestre em Educação pela Pontifícia Universidade Católica do Rio Grande do Sul (1995) e Doutora em Informática na Educação pela Universidade Federal do Rio Grande do Sul (2004). Atualmente é professora adjunta da Universidade Luterana do Brasil, atuando no curso de Pedagogia e no Programa de PósGraduação em Ensino de Ciências e Matemática. E-mail: marlise.geller@gmail.com
} 


\section{INTRODUÇÃO}

Como parte do currículo escolar, cabe ao professor dos primeiros anos do Ensino Fundamental proporcionar aos alunos a construção do número, encorajando-os a quantificar, comparar quantidades e operar com elas. Para o aluno surdo dessa etapa da escolaridade, esse nem sempre é um processo de aprendizagem fácil, pois muitos desses alunos, ao mesmo tempo em que buscam compreender os conceitos matemáticos, estão iniciando a aprendizagem de sua língua materna: a Libras. Os mesmos dedos da mão que são utilizados pelo aluno como apoio para realizar contagens também são empregados na sinalização dos números em Libras.

O documento do MEC que traz orientações para o Ensino Fundamental de nove anos (BRASIL, 2006) esclarece que as crianças de seis anos, assim como as demais de sete a dez anos de idade, faixa etária em que se encontram os alunos desta investigação, precisam de uma proposta curricular que atenda as suas características, potencialidades e necessidades específicas. Alerta que, para isso, faz-se necessário um trabalho pedagógico que assegure o estudo das diversas expressões e de todas as áreas do conhecimento e tal tarefa requer atitude de curiosidade científica e de reflexão, de investigação sobre o que sabemos a respeito de inquietude e de fazeres pedagógicos bem constituídos.

“Quais propostas de ensino são consideradas pertinentes à construção dos conceitos numéricos iniciais dos alunos surdos que estão nos dois primeiros anos do Ensino Fundamental?", ao assumir este problema de pesquisa, articulado ao objetivo de investigar ações pedagógicas no âmbito da Matemática envolvendo materiais de apoio para o trabalho com estes alunos, este artigo relata um recorte dos resultados de uma pesquisa realizada com uma turma de alunos surdos ao longo do $1^{\circ}$ e do $2^{\circ}$ Anos do Ensino Fundamental, em uma parceria, entre a professora de Informática e a professora regente da turma, por meio da elaboração e da aplicação de atividades matemáticas que pudessem auxiliar a aprendizagem dos conceitos numéricos junto a estes alunos (RODRIGUES, 2013).

Para apoiar a atividade docente ao longo da pesquisa, é necessário resgatar algumas premissas da educação de surdos no Brasil, que se configurou basicamente por três abordagens comunicacionais no ensino: Oralismo, Comunicação Total e o Bilinguismo.

Resumidamente, no oralismo assume-se que a maneira mais eficaz de se educar o surdo é por meio da língua oral. Na comunicação total as línguas de sinais foram empregadas com outros meios, como a fala, treino auditivo, leitura labial, aparelhos auditivos, implantes cocleares, recursos visuais, datilologia (soletração em língua de 
sinais), bimodalismo (sinais e fala), português sinalizado (sinalização com estrutura do português). (GOLDFELD, 2002; SLOMSKI, 2010).

O bilinguismo é a abordagem recomendada atualmente na educação de surdos. Consiste na aprendizagem da língua de sinais como primeira língua do surdo e a língua portuguesa como segunda língua na sua modalidade escrita (CAPOVILLA, 2008).

No Brasil, somente em 2002 a Libras - Língua Brasileira de Sinais - foi reconhecida como meio legal de comunicação e expressão do surdo, pela Lei $\mathrm{N}^{\mathrm{o}} 10.436$ e regulamentada em 22 de dezembro de 2005, pela Lei No 5.626. (BRASIL, 2005).

\section{ENSINO FUNDAMENTAL DE NOVE ANOS E A CRIANÇA SURDA}

A inclusão das crianças de seis anos no Ensino Fundamental amplia a escolarização para uma parcela significativa da população brasileira que se encontrava, até então, privada da educação escolar ou sem garantia de vagas nas instituições públicas de ensino. Junto a essa parcela significativa estão as crianças surdas que ingressam, na maioria das vezes, por volta dos sete anos de idade à escola, quando não depois dessa idade, e, na maioria das vezes, é quando ocorre seu primeiro contato com a língua materna: a Libras.

Considerando esse fato e o de que, quanto mais cedo o indivíduo surdo for exposto a sua língua materna, melhores serão suas chances de um positivo desenvolvimento social e cognitivo (QUADROS, 1997).

O Ensino Fundamental ao ter sua duração ampliada de oito para nove anos, traz para a escola um grupo de crianças que, ao serem introduzidas nessas instituições, entram em contato com uma cultura da qual devem se apropriar. A maioria das crianças surdas são filhas de pais ouvintes que normalmente não conhecem a língua de sinais e, muitas vezes, nunca viram outro surdo (QUADROS; CRUZ, 2011), em consequência, será na escola o primeiro contato com uma comunidade surda. (LOPES, 2007).

Outra consideração quanto a essa ampliação, ainda que algumas das crianças de seis anos já frequentassem instituições pré-escolares, a entrada delas no Ensino Fundamental passa a impor novos desafios, sobretudo pedagógicos, para a área educacional. A construção dessa prática educativa deve ter a criança como eixo do processo e levar em conta as diferentes dimensões de sua formação. Muitas das crianças surdas começaram sua vida escolar por volta dos sete ou oito anos de idade, o que com o Ensino de nove anos, atualmente, acontece mais cedo. Então é nessa idade, quando essas crianças chegam pela primeira vez na escola, que terão seu primeiro contato com a Libras. 
Dessa forma, o professor que atuará com essas crianças terá de levar em conta que a comunicação deve se dar por meio da Libras e que esta apenas agora se inicia.

As brincadeiras espontâneas, o uso de materiais, os jogos, as múltiplas formas de comunicação, de expressão, de criação e de movimento são experiências dirigidas que exigem que o conhecimento dos limites e alcances das crianças e dos adultos esteja contemplado (BRASIL, 2005).

Nesse sentido, a construção e/ou exploração de materiais concretos e digitais didáticos próprios dessa fase pode auxiliar no processo de ensino e aprendizagem dessas crianças, principalmente quando se trata de crianças surdas, pois, conforme Rosa (2006), o Brasil carece de muitos materiais didáticos direcionados para os surdos.

Além disso, é importante que o trabalho pedagógico com as crianças de seis anos de idade, nos anos iniciais do Ensino Fundamental, busque a articulação entre as Ciências Sociais, as Ciências Naturais, as Noções Lógico-Matemáticas e as Linguagens (BRASIL, 2006).

Buscando assegurar aos aprendizes o pleno desenvolvimento de suas potencialidades é fundamental, dentre outros aspectos, que a ação educativa se baseie em uma orientação teórico-metodológica, que se definam os objetivos de ensino, a organização do trabalho pedagógico, o tipo de abordagem que se quer dar ao conhecimento e, por fim, que se considere a realidade sociocultural dos alunos e o contexto da escola.

Assim, essa configuração da Educação Básica pode trazer importantes contribuições no processo de desenvolvimento do aluno surdo, pois pode antecipar ou aprofundar o processo de alfabetização da Libras.

\section{A MATEMÁTICA NA EDUCAÇÃO DE SURDOS}

Há pesquisas realizadas na educação de alunos surdos que apontam características essenciais relacionadas ao ensino da Matemática a esses alunos. Dentre elas, Fávero e Pimenta apontam três aspectos fundamentais:

(a) o professor (ou outro profissional) que lida com surdos deve ter fluência em Libras; (b) as estratégias de ensino e de matemática devem favorecer experiências significativas para o aluno; (c) o aluno deve ter, no seu processo de escolarização, a oportunidade de lidar com diferentes funções do número. (FÁVERO; PIMENTA, 2006, p. 231). 
Madalena (1997) considera que, para as crianças surdas, a Matemática é um sistema de representação assim como a língua materna, cujo significado se constrói nas ações e nas relações com o outro.

Arnoldo Junior (2010) empregou o Multiplano para ensinar conceitos de geometria plana para alunos do Ensino Fundamental. Demonstrou em sua pesquisa que o Multiplano é um recurso didático que contribuiu para o desenvolvimento do pensamento geométrico, a mediação do conhecimento, a estimulação à criatividade, a diminuição de barreiras comunicativas por compensações sígnicas, a criação de zona de desenvolvimento proximal e a possibilidade de nelas intervir, atuando em posições de não-aprendizagem. Segundo este autor, o Multiplano configurou-se em um instrumento cultural que atende as necessidades da cultura surda para a aprendizagem em Matemática.

Oliveira (2005) utilizou o origami para ensinar geometria para alunos surdos do ensino fundamental. A autora salienta que para acontecer o aprendizado em uma classe de surdos, o educador deve estar apoiado em um tripé educacional: a Língua de Sinais, o conhecimento Matemático e uma metodologia apropriada. Completa, ainda, que para que o educador atenda as expectativas desses estudantes, é preciso colocar-se em seu lugar, imaginar como se dá a construção do conhecimento para um indivíduo desprovido do sentido da audição.

Sales (2008) analisou as evidências apresentadas pelos alunos surdos e pesquisadores, por meio de ações reflexivas no processo de ensino com resolução de problemas aditivos, proporcionado pela Libras, e que demonstrassem ser indícios de envolvimento e de aprendizagem. Constatou que o ambiente proporcionado pela resolução de problemas aditivos, por meio da língua de sinais associados a alguns recursos didáticos, permite estabelecer um canal de comunicação favorável para que os sujeitos interagissem com seus pares e também com o grupo.

Sales $(2008$, p. 21) reforça a necessidade de que se proporcione à criança surda, "iguais possibilidades de observação, compreensão e expressão social, acadêmica e cultural", levando em consideração que o acesso lhe seja facilitado na proporção das “dificuldades e/ou limitações criadas pela cultura ouvinte". Conclui, dizendo que o surdo precisa ter contato, o mais breve possível, com uma língua de sinais, assim, apropriando e interagindo por meio desta, não necessitaria de "metodologias especiais de aprendizagem".

Bastos e Pereira (2009) analisaram a aprendizagem de surdos de Ensino Médio mediante o emprego de situações-problemas. Para isso, empregaram recursos visuais 
(gravuras e fotos), como promovedores da aprendizagem de conceitos matemáticos. Perceberam que o ensino de situações-problema enfatiza a interação entre conceitos matemáticos, ação, observação e análise, minimizando os processos operatórios de forma mecânica, possibilitando desenvolver um conhecimento teórico e prático mais integrado, tornando as práticas escolares de Matemática mais motivadoras e dinâmicas.

É de consenso dos pesquisadores citados que o recurso facilita o processo de ensino e aprendizagem da Matemática, mas para uma educação de qualidade não é o bastante, o professor também deve dominar os conhecimentos matemáticos, buscar estratégias metodológicas que deem conta de oportunizar ao aluno construir seu conhecimento e, não menos importante, dominar a língua de sinais, e ao utilizar materiais de apoio ao ensino tenha bem claro os objetivos que pretende atingir e como pretende atingi-lo.

$\mathrm{Na}$ Matemática, o sucesso ou o fracasso dos alunos dependem das relações estabelecidas entre o professor, o aluno e o conhecimento. Dar aulas é diferente de ensinar. Ao ensinar o aluno, devem-se oferecer condições para que o mesmo construa seu próprio conhecimento (LORENZATO, 2006). É importante ter em mente a concepção de que somente ocorre ensino se houver aprendizagem, pois é possível dar aula sem ter conhecimento, porém não é possível ensinar sem ter conhecimento.

\section{MATERIAIS DIGITAIS COMO APOIO AO ENSINO DE MATEMÁTICA}

As crianças estão imersas nesse mundo tecnológico e seus interesses e padrões de pensamento já fazem parte desse universo (WEISS; CRUZ, 1999). Nessa proposta, fazer uso adequado do computador no ambiente escolar pode contribuir para um maior envolvimento do aluno com sua aprendizagem. Assim, cabe ao professor escolher os materiais que melhor adaptam-se aos seus alunos e aos objetivos que pretende atingir. Para isso, uma opção está na elaboração do próprio material didático a ser utilizado com os alunos. É importante que esse material possibilite a interação do aluno e lhe permita verificações e possibilidades de tomadas de decisões.

Alguns cuidados são necessários na elaboração desse material, como as competências pertinentes ao professor para esse trabalho, a interação com uma equipe multidisciplinar e a disponibilidade de softwares adequados ao que se pretende realizar. 
Um software que tem colaborado para esse contexto é o Jclic ${ }^{3}$, um software de autoria de uso livre, que permite ao professor, ou ao aluno, criar atividades interativas das diversas áreas do currículo, possibilitando a integração com som, imagem e vídeo. É constituído por um conjunto de aplicações que são utilizadas na criação, realização e avaliação de atividades didáticas e disponibiliza sete tipos de atividades básicas: associações; jogos de memória; exploração, identificador de células e tela de informação; quebra-cabeça (puzzle); atividades de resposta escrita; exercícios com texto; caça-palavras e palavras cruzadas.

Buscando explorar e problematizar o uso de materiais didáticos de apoio ao ensino de conceitos numéricos para alunos surdos dos primeiros anos do Ensino Fundamental, optou-se pelo Jclic por ser um software que oferece recursos de inserção de imagens e vídeos que poderiam contribuir para uma proposta bilíngue no ensino da Matemática.

\section{O PERCURSO METODOLÓGICO}

Com o intuito de refletir sobre estratégias de ensino empregadas na construção dos conceitos numéricos iniciais com alunos surdos dos dois primeiros anos do Ensino Fundamental, optou-se por uma abordagem qualitativa, utilizando o método exploratório descritivo e explicativo (GIL, 2008).

A coleta de dados ocorreu por meio de observações em sala de aula, registros de filmagens das atividades desenvolvidas durante as aulas de Matemática e Informática, com a devida autorização dos professores e dos pais dos alunos, a partir do Termo de Autorização do Uso dos Depoimentos e Imagens (RODRIGUES, 2013). O registro de filmagens de aulas, questionários e entrevistas são procedimentos utilizados na investigação social, para a coleta de dados ou para ajudar no diagnóstico ou no tratamento de um problema social. (MARCONI; LAKATOS, 2007).

A pesquisa foi conduzida em uma associação especializada na educação de surdos com ensino bilíngue, localizada na região metropolitana de Porto Alegre. Participaram desta pesquisa sete sujeitos, sendo quatro alunos surdos com idades entre 7 e 9 anos, nomeados de Aluno 1, Aluno 2, Aluno 3 e Aluno 4 e duas professoras, sendo a Professora A, professora titular da turma, e Professora B, professora de Informática, com formação em Matemática.

\footnotetext{
${ }^{3}$ Informações sobre o Jclic podem ser encontradas no site http://clic.xtec.cat/es/jclic/index.htm
} 
Para o planejamento das aulas de Matemática, a Professora A utilizou diferentes materiais concretos para abordar os conceitos numéricos iniciais: base dez, balas, pirulitos, oportunizou saídas da sala de aula para compras no supermercado, lojas, cantina da escola. Esta professora apontou a sequência numérica e a relação numeral/quantidade/libras como as principais dificuldades dos alunos.

\section{ANÁLISE DOS RESULTADOS}

Neste artigo é apresentado um recorte das categorias de análise da pesquisa, definidas a partir das observações e transcrições dos vídeos, envolvendo a comunicação em sala de aula e o uso de materiais digitais de apoio ao ensino dos conceitos numéricos.

\subsection{A comunicação em sala de aula}

Esta categoria trata de uma das atividades desenvolvidas pela Professora A com os Alunos 1, 2 e 3. Estudando palavras com a letra p, levou a turma a uma loja próxima à escola para comprar pirulitos. Os alunos ajudaram a professora a organizar o dinheiro para pagar os pirulitos, comeram alguns e deram alguns a amigos surdos de outras turmas, restando apenas dez.

Professora A: [Nós fomos à loja e compramos pirulitos...] (a professora pega então o pacote de pirulitos e mostra aos alunos) [...como é mesmo o nome deste pirulito?] (questiona, apontando para a figura do Piu-piu, que está estampada no pacote de pirulitos).

Aluno 1 e aluno 2: P-I-U- -P-I-U (O Aluno 3 observa)

Professora A: [muito bem, falem o nome dele]

Aluno 2: piu-piu (com um pouco de dificuldade)

Aluno 3: [pã] P - [pã] I - [pã] U (faz sons com a boca para cada letra da palavra piu, sinalizando em alfabeto manual a palavra piu)

Aluno 1: [piu-piu]

Professora A: (tira os 10 pirulitos que ainda havia dentro do pacote e coloca-os sobre a mesa, mostrando aos alunos que o pacote então ficou vazio) [Aluno 1, conta quantos pirulitos têm?]

(todos querem contar, mas a professora mostra que neste momento é apenas o Aluno 1 que contará)

Aluno 1: [um, dois, três, ..., dez] (sinaliza e fala os números enquanto conta até dez, associando a cada pirulito um sinal da sequência numérica)

Professora A: [10? Então vamos separar para contar] (mostra ao Aluno 1 que quer que separe os pirulitos um a um, distanciando os contados dos não contados e sinalizando e falando cada número da contagem)

Aluno 1: $[1,2,3,4,5,6,7,8,9]$ (sinaliza 9, pára no próximo pirulito, olha para a professora como se precisasse de sua aprovação e então sinaliza 10, a professora confirma com a cabeça que é 10 e suspira)

Professora A: [tem dez pirulitos que sobrou e os outros pirulitos que estavam aqui onde estão? Quantos tinham?] (nesse momento a professora fala mais do que sinaliza, percebe-se que apenas o Aluno 1 entende o que foi questionado) 
Aluno 2: NADA (responde após a professora colocar o pacote vazio sobre a mesa)

Aluno 1: CINQUENTA (mostra no pacote o número cinquenta e sinaliza-o)

Professora A: [e os outros onde estão?]

Aluno 1: ONDE?

Aluno 2: COMEMOS!

Professora A: [vocês comeram, isso mesmo, agora só tem 10!]

Buscou-se analisar como ocorreram as formas de comunicação durante as aulas de Matemática, procurando discutir e refletir sobre as abordagens educacionais existentes no Brasil.

Primeiramente, podemos observar que o ambiente organizado pela professora para trabalhar com os alunos, em uma mesa redonda e todos sentados a sua volta, favorece a interação social, contribuindo para uma melhor comunicação entre o grupo. Essa organização é possível pela quantidade de alunos que é significativamente pequeno.

A partir das observações dos vídeos, verificou-se interações da professora A com seus alunos, constatando que a comunicação entre estes é pautada por meio da Libras e na Língua Portuguesa falada. Poderia essa ação de ensino aos surdos ser um retrocesso à Comunicação Total?

Em encontros realizados com a professora A, a mesma justificou a abordagem educacional que utiliza em sala de aula, relatando que considera importante usar a fala juntamente com a Libras, pois essa combinação faz com que os alunos que contam com resto auditivo tenham acesso às duas vias de comunicação (fala e sinais). Além desse motivo, a professora também acredita que a alfabetização de surdos se dá mais facilmente com um método bilíngue e, então, procura dar ao seu aluno, com surdez profunda, a oportunidade de adquirir uma leitura labial, procurando facilitar sua comunicação com o resto da sociedade oralista.

Segundo a supervisora da escola, a instituição foi inaugurada em 1993 e a comunicação utilizada nessa época na instituição de ensino era a Comunicação Total. Os alunos eram estimulados ao uso tanto da língua de sinais como da oralização e do português escrito, inclusive participavam de aulas com fonoaudióloga, utilizando diversos aparelhos de estímulo auditivo. Conta que, atualmente, as aulas acontecem por meio do bilinguismo, mas alguns professores ainda falam enquanto sinalizam.

O uso simultâneo de fala e sinais (bimodalismo), do estímulo à leitura labial, são características da Comunicação Total. De acordo com a história da educação de surdos no Brasil, essa abordagem educacional tinha por maior objetivo auxiliar a compreensão da 
língua falada e, assim, melhorar o desempenho do surdo na leitura e na escrita (CAPOVILLA, 2008).

Com base na justificativa da professora em "dar ao seu aluno com surdez profunda a oportunidade de adquirir uma leitura labial" pode-se observar a intenção da professora na oralização de seus alunos. Como essa oralização é mediada pela Língua de Sinais, a abordagem que melhor se configura nessa característica é a Comunicação Total.

No trecho de aula descrito anteriormente, pode-se observar também que o Aluno 1, que conta com um resto auditivo, consegue entender e corresponder oralmente aos questionamentos da professora, enquanto os outros alunos entendem o que captam visualmente, seja por meio da Libras ou dos objetos que lhes foram mostrados. Um exemplo ocorreu quando a Professora A indagou sobre quantos pirulitos havia inicialmente no pacote e o aluno 2 respondeu "NADA".

Para Machado (2009), a educação bilíngue (Libras e Língua Portuguesa), no que diz respeito à Língua Portuguesa, refere-se a uma modalidade escrita e a fluência da Língua Portuguesa falada não é o fator principal a essa classificação. Esse autor defende que se deve olhar os surdos enquanto surdos e, para isso faz-se necessário conhecer elementos definidores dessa norma que são dados e significados na linguagem e na cultura. Completa que, apesar de ser claro para muitos que a língua de sinais é um traço fundamental para estabelecer um sujeito surdo de ser, ainda assim não é significativamente compreendida pela escola como elemento fundamental na constituição do sujeito surdo.

Alguns autores criticam o uso da Comunicação Total na educação atual (ARNOLDO JUNIOR, 2010; SANTANA, 2007), pois apoiam o Bilinguismo como proposta educacional favorável aos surdos, defendendo a Libras como uma Língua que possui estrutura própria e que precisa ser respeitada.

Lopes (2007) e Skliar (1997) apontam que os surdos pertencem a uma comunidade surda e esta defende a proposta do bilinguismo, reconhecendo seu direito de aquisição e uso das línguas de sinais não para serem oralizadas, mas sim para poderem participar, em igualdade de condições, com sua própria língua dos debates que circulam na sociedade.

Skliar (1999) acredita que uma proposta educacional bilíngue aos surdos deve levar em consideração o reconhecimento da diferença cultural surda, e também o reconhecimento da língua de sinais, como sendo própria da comunidade à qual pertence o sujeito surdo. 
Outro fato apontado pela professora para justificar a fala em suas aulas é que a mesma acredita que a alfabetização da Língua Portuguesa de surdos se dá mais facilmente com um "método bilíngue". Nesse sentido, remetemo-nos a Skliar (1997, p. 38) que o que se observa no âmbito escolar é a proposta de "reverter a típica sequência língua oral-língua escrita, pela sequência língua de sinais - língua oral - língua escrita e/ou pela sequência língua de sinais - língua escrita - língua oral”. Machado (2009, p.65) corrobora apontando que todo currículo segue refém dessa lógica, permanecendo preso aos objetivos de sequências linguísticas e os "mecanismos colonizadores exercidos pela ideologia subjacente ao projeto oralista".

Quadros (1997) indica esse fato como uma das formas do Bilinguismo em que o ensino da segunda língua acontece quase que concomitante com a primeira, no entanto diz ser uma forma questionável, pois ocorre a aprendizagem de duas línguas diferentes simultaneamente. A autora apoia o ensino da segunda língua somente após a aquisição da primeira, podendo ser efetivado de duas maneiras, em que a primeira, o ensino da língua oral-auditiva, se dá por meio da leitura e escrita; a segunda possibilidade é o ensino da oralização, além da leitura e da escrita.

Tem-se ainda nesse cenário a preocupação da professora em oportunizar aos "alunos que contam com resto auditivo" o acesso às duas vias de comunicação (fala e sinais). Cabe lembrar, nesse momento, que o Aluno 1, a quem essa professora refere-se, possui um resto auditivo e está em fase inicial de aprendizagem da Libras, ou seja, torna-se relevante que a ele também seja oportunizado o estímulo auditivo, que se leve em conta suas peculiaridades.

Como comenta Gesser (2009), a oralização deixou marcas profundas na vida da maioria dos surdos, por isso há uma rejeição da oralização a todo custo por surdos mais politizados e militantes, mas que essa é mais uma discussão político-ideológica e pertinente para a visualização da Libras. $\mathrm{O}$ autor conclui dizendo que se houver o respeito à língua de sinais e o direito do surdo a ser educado em sinais, deve-se também respeitar o direito daqueles surdos que optam por também falar (oralizar) a Língua Portuguesa.

\section{MATERIAIS DIGITAIS EM UMA ABORDAGEM BILÍNGUE}

Esta análise pretende refletir sobre o uso de materiais digitais como auxílio no ensino da Matemática. A ferramenta escolhida foi o software de autoria Jclic. Devido à 
escassez de materiais digitais que contemplem uma abordagem bilíngue, buscou-se neste software contribuições para o desenvolvimento de atividades que possam favorecer a aquisição dos conceitos numéricos iniciais.

Assim, realizou-se uma parceria entre a professora titular da turma, Professora A, e a professora de Informática, Professora B. As atividades foram elaboradas após conversa com a professora A que comentava o que gostaria que os alunos explorassem na Informática e foram desenvolvidas por meio de uma abordagem bilíngue. Algumas atividades estão disponíveis na biblioteca de atividades do $\mathrm{ZonaClic}^{4}$.

\section{- Atividades com vídeos:}

Cada projeto Jclic contava com a produção de vídeos para apresentação dos projetos. Os vídeos foram produzidos na sala de Informática, pela Professora B, utilizando uma filmadora e um projetor que reproduzia, no quadro branco, as atividades criadas. $\mathrm{O}$ vídeo foi produzido em Libras, visando o entendimento e autonomia dos alunos na realização das tarefas. Kamii (2004) aponta que uma das finalidades da educação deve ser a de desenvolver a autonomia da criança, que é, indissociavelmente, social, moral e intelectual e que a aritmética, assim como qualquer outra matéria, deve ser ensinada no contexto desse objetivo amplo.

\section{- Atividades com Imagens:}

Para os surdos, o artefato visual é considerado um dos principais facilitadores do desenvolvimento da aprendizagem (SALES, 2008). Assim, privilegiar recursos visoespaciais nas estratégias metodológicas é de suma importância. A fim de contribuir para esse contexto e procurando levar em consideração a questão dos direitos autorais de imagens, foram utilizadas na elaboração dos projetos Jclic algumas imagens, descritas a seguir.

Essas imagens (figura 1) contribuíram significativamente no desenvolvimento das atividades, pois oportunizaram aos alunos visualizar não somente os símbolos matemáticos e o nome dos números em Português, mas também a representação do número em Libras.

\footnotetext{
${ }^{4}$ http://clic.xtec.cat/db/listact_en.jsp
} 


\section{Figura 1 - Desenho dos números}
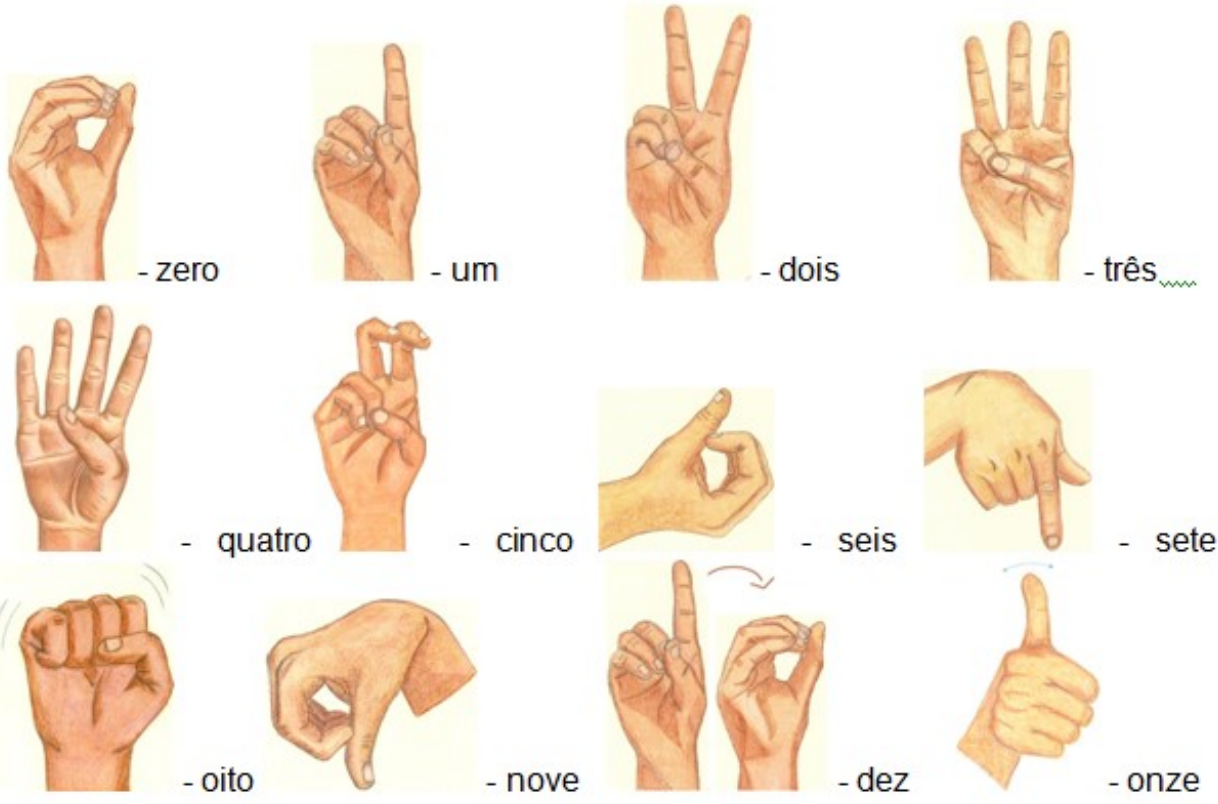

Fonte: A pesquisa.

As imagens (figura 2), utilizadas nos projetos Jclic, foram feitas pelos próprios alunos da turma que, primeiramente, as produziram em aulas de artes de acordo com os temas estudados pela turma com a professora A. Em seguida, foram digitalizadas e, então, empregadas nas atividades do Jclic, com a intenção de envolver ainda mais os alunos nas tarefas propostas.

Figura 2 - Atividade do Jclic com imagens dos alunos e os números em Libras

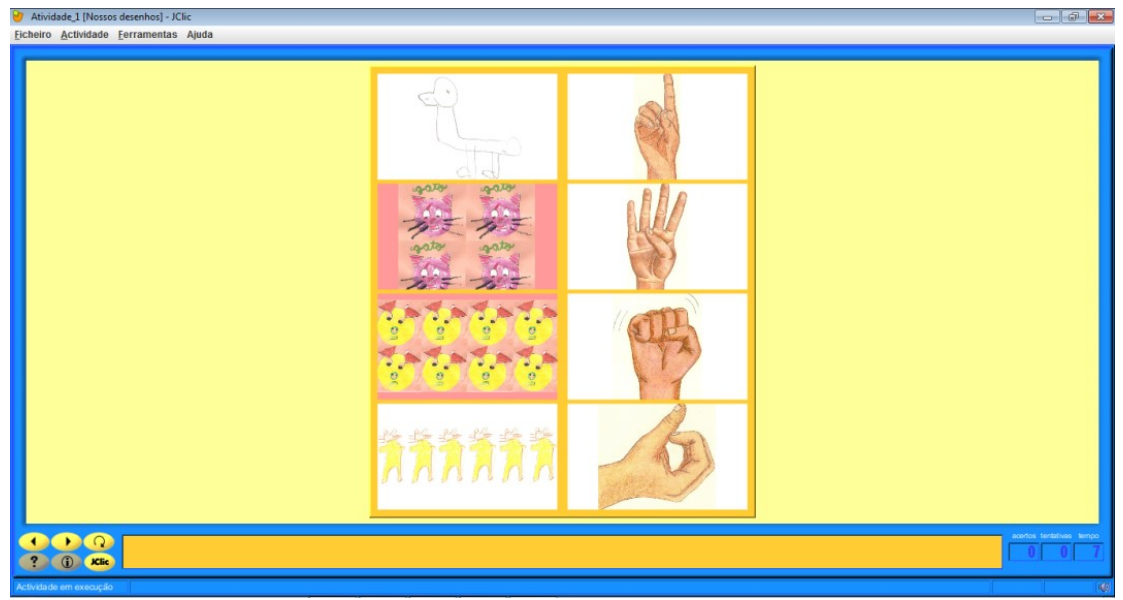

Fonte: A pesquisa. 
Pode-se perceber nos vídeos o quanto os alunos ficaram motivados durante a realização das tarefas ao perceberem seus próprios desenhos em meio a elas, comparandoos e buscando saber de quem era cada desenho.

\section{- Gifs animados ${ }^{5}$ :}

A possibilidade da colocação de gifs nas mensagens das atividades caracterizou ainda mais um ambiente bilíngue. Para produção dos gifs a Professora B em parceria com outra professora da escola, criaram alguns gifs em Libras, utilizando sequência de fotos e o programa animator.

Figura 3 - Gif do sinal "parabéns"

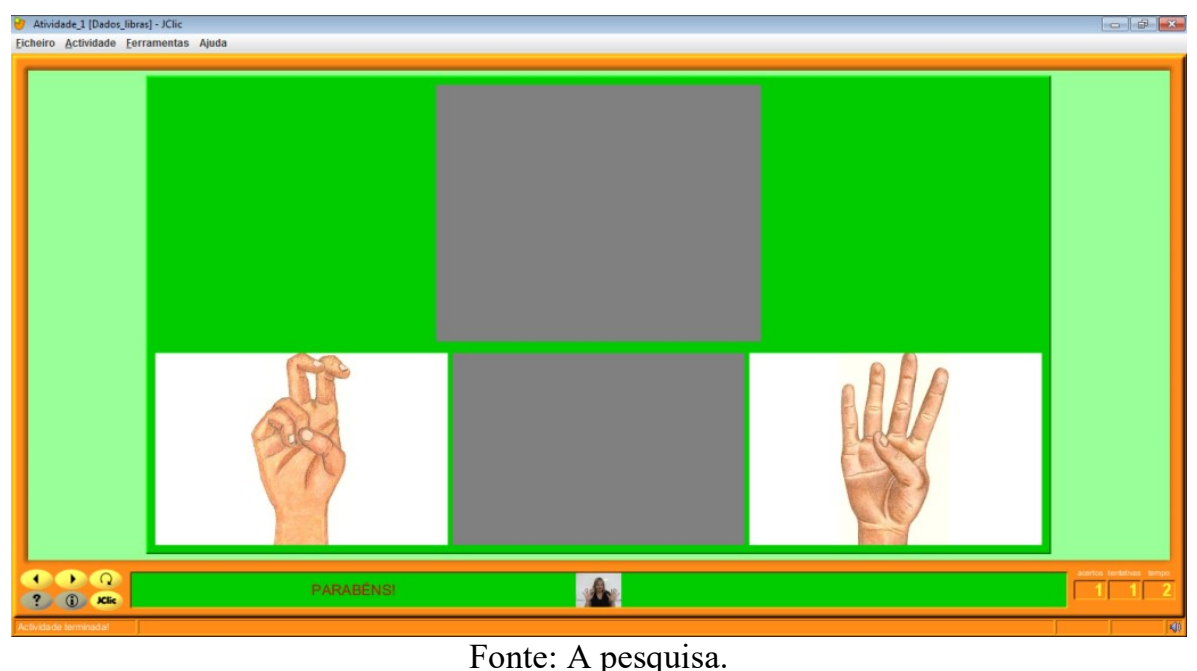

Novamente o software Jclic, agora com a oferta de inserção de gifs, possibilitou um enfoque bilíngue ao projeto. Ao lado do gif em Libras, encontra-se também a mensagem em português. Além desses recursos, o Jclic ofereceu diferentes possibilidades na realização de atividades lúdicas, como jogo da memória, quebra-cabeça, associações.

Considerando o desenvolvimento dos alunos nesta etapa do Ensino Fundamental, o jogo é vantajoso uma vez que possibilita compreensão, formam hábitos e se estruturam num sistema de regras. A criança quando joga experimenta competências cognitivas, psicomotoras, realizando diversas operações mentais, da mesma forma com os materiais concretos. A seguir são indicados os diferentes aplicativos explorados com os alunos durante as aulas de Informática:

\footnotetext{
${ }^{5}$ Gif animado é o termo dado às animações formadas por várias imagens compactadas em uma só. A sequência de imagens dá a ilusão de movimento.
} 
- Associação Simples: apresentam-se dois conjuntos de informação que possuem o mesmo número de elementos. A cada elemento do primeiro conjunto corresponde um elemento do segundo conjunto.

Figura 4 - Atividade de associação simples

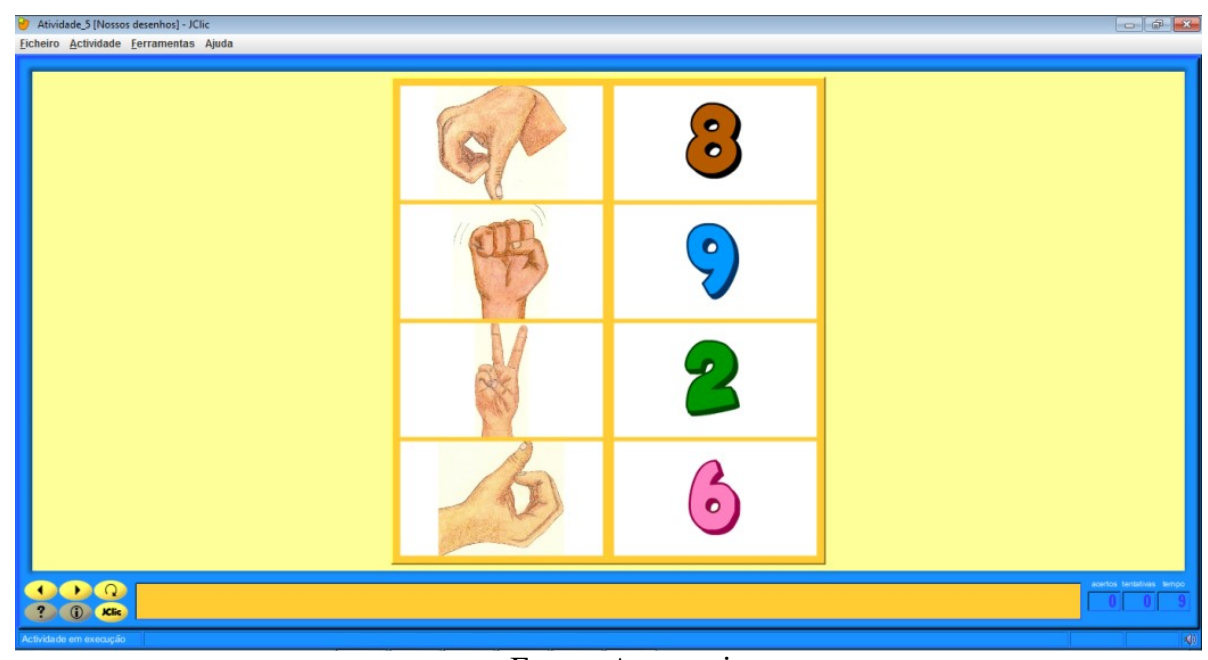

Fonte: A pesquisa.

- Associação Complexa: apresentam-se dois conjuntos de informação, mas estes podem ter um número diferente de elementos e entre eles podem existir diversos tipos de relação: um a um, diversos a um, elementos sem relação com outro elemento.

Figura 5 - Atividade de associação complexa

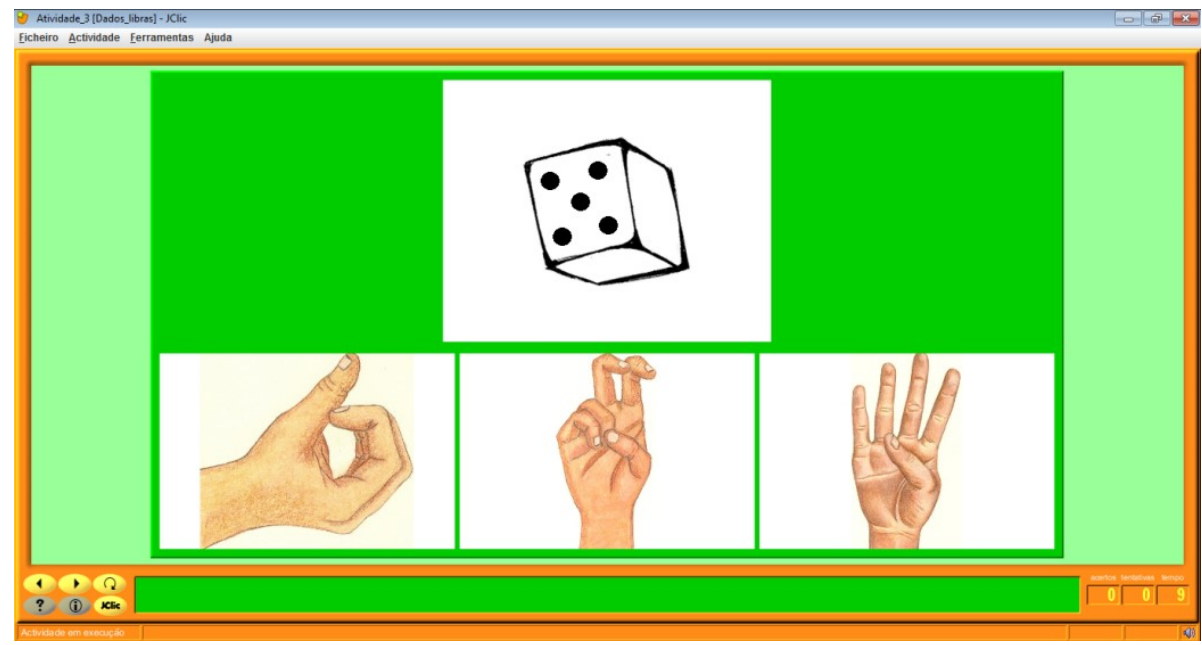

Fonte: A pesquisa.

- Jogo da Memória: nesse tipo de atividade é preciso descobrir pares de elementos entre um conjunto de peças inicialmente escondidas. Os pares podem estar formados por duas peças iguais ou por dois elementos relacionados. 
Figura 6 - Atividade de memória

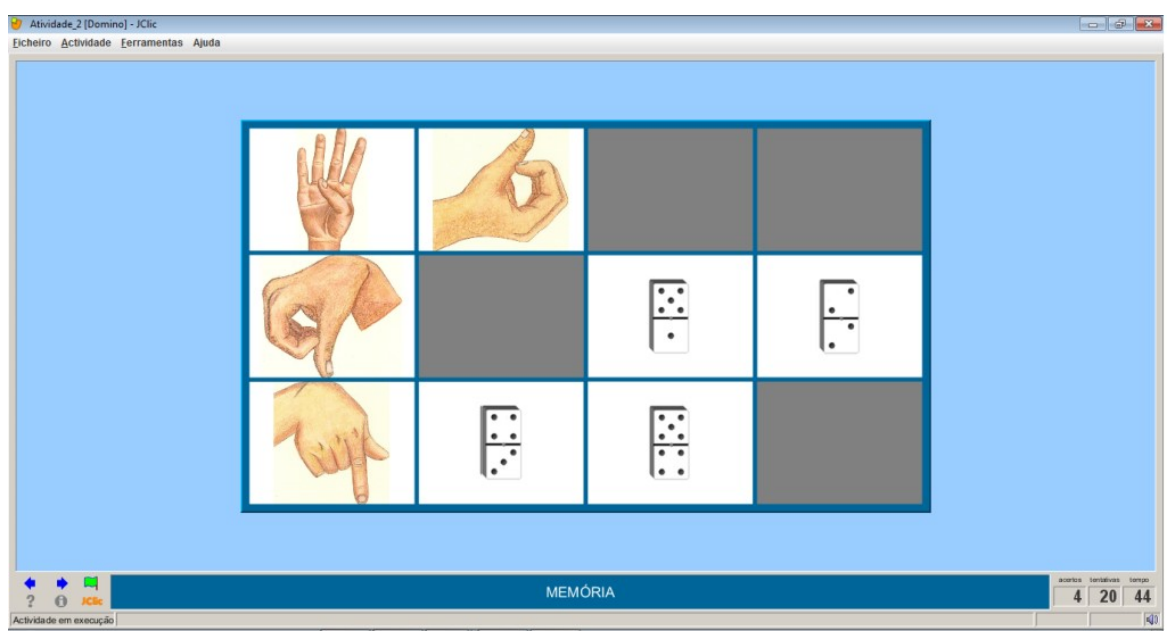

Fonte: A pesquisa.

- Quebra-cabeça: planeja a construção de uma informação que está inicialmente desordenada.

Figura 7 - Atividade de quebra-cabeça

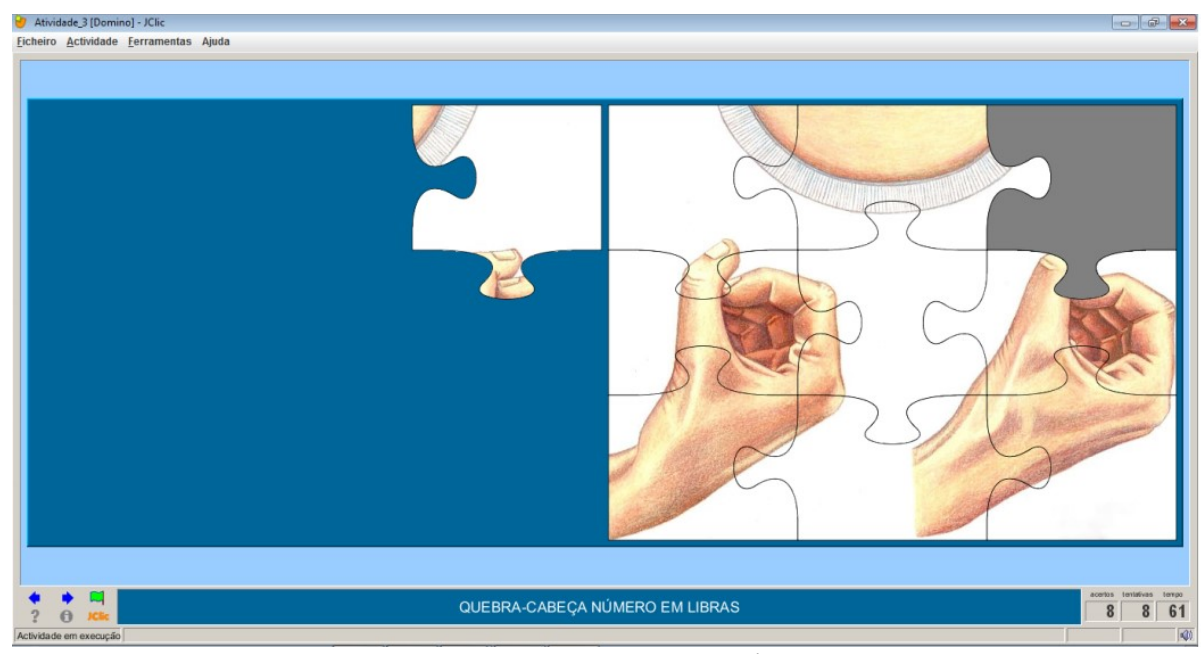

Fonte: A pesquisa.

Durante o desenvolvimento das atividades, a Professora B objetivou a autonomia do aluno frente à ferramenta e seus recursos, condensados em projetos. Para tanto, procurou dar autonomia aos alunos na realização das tarefas, atuando como observadora e mediadora do processo, quando necessário. Os alunos assistiam ao vídeo inicial, em Libras, quantas vezes fossem necessárias para o seu entendimento. Em seguida, realizavam as tarefas, ora realizavam individualmente, ora trocavam ideias com os colegas ou ainda questionavam a Professora B. 
As atividades foram extensões das realizadas em aula, como associar a imagem de dois dados, cujas faces superiores apresentavam bolinhas representando quantidades à sua respectiva soma, quantificar os cubinhos do material dourado, comparar quantidades, apresentadas ludicamente, em que o aluno poderia desenvolver as ideias da adição, da quantificação, agora ofertadas em outro ambiente, buscando a interação com os colegas e com a professora e a possibilidade de desenvolvimento dos conceitos numéricos.

Em uma das aulas, descrita a seguir, pode-se observar a importância da interação entre os colegas e que essa interação também pode ser promovida durante o uso do computador, mais propriamente dito, durante o desenvolvimento das atividades do Jclic. Nessa aula, o Aluno 3, ao realizar uma atividade de associação de quantidades com sua respectiva representação em Libras, percebe que o valor encontrado não está entre as opções propostas. Conta de novo. Não encontra o valor. Mostra para o Aluno 4, ao seu lado, que não tem o valor encontrado entre as opções. O Aluno 4 conta junto com ele, então o Aluno 3 percebe e diz para o Aluno 4 que esqueceu de contar o seis, pulou do cinco para o sete. Nesse sentido, Kamii (2004) contribui dizendo que a criança, ao ter a oportunidade de discutir com outra criança sobre o seu pensamento, pode reexaminar suas próprias ideias, oportunizando a correção do seu próprio pensamento.

Outro fato observado é que as atividades envolvendo conceitos numéricos produzidas no Jclic contribuíram para o aluno construir seus próprios conhecimentos. $\mathrm{Ou}$ seja, esse ambiente também pode ser explorado como um facilitador do ensino de conceitos numéricos iniciais. Uma das situações em que este pode ser observado foi na aplicação de um dos projetos do Jclic que envolvia o material dourado. A proposta foi a de relacionar quantidades, representadas pelas barrinhas e cubinhos, pelo número correspondente em Libras. O Aluno 1, por diversas vezes, contou os cubinhos da barrinha um a um para compor o número correspondente aquela quantidade, ou seja, pensando "um 10" ou "10 uns" separadamente. Em um determinado momento, começou a contar cada barrinha a partir de dez, ou seja, começou a pensar "um 10" e "10 uns" simultaneamente. Nas próximas atividades, ainda oscilava entre os "10 uns" e "um 10", ora separadamente, ora simultaneamente. Foi o início de uma relação construída pelo próprio aluno, sendo oportunizado a ele o desenvolvimento de tarefas que poderiam facilitar esse processo, mas não garantir a construção dessa relação. Foram relações construídas pelo Aluno 1, ao seu tempo, ao seu ritmo, favorecidas pelo ambiente facilitador desse processo. 
As atividades propostas na Informática possibilitaram verificar que o Jclic é um software que pode oferecer recursos para o desenvolvimento de atividades que visam contribuir para a construção dos conceitos numéricos pelos alunos, por meio de uma abordagem bilíngue, além da constituição de um ambiente estimulador e facilitador no processo de ensino da Matemática.

\section{CONCLUSÕES}

Neste recorte da investigação, discutiu-se a comunicação do professor com seus alunos frente às diferentes abordagens comunicacionais existentes na educação de surdos no Brasil. Dessa análise, salienta-se a importância da Libras como língua mediadora no processo educacional. O bilinguismo é a abordagem que melhor favorece a comunicação e, consequentemente, a educação dos surdos, com esta abordagem de ensino os professores ministram suas aulas em língua de sinais, sendo por meio desta que os alunos compreenderão o mundo que os cerca.

As potencialidades do software Jclic foram evidenciadas na construção de atividades que visaram à construção de conceitos numéricos, por meio de uma proposta bilíngue. A exploração do software e a observação dos alunos na resolução das atividades possibilitam verificar que esse aplicativo oferece recursos que permitem a inserção de vídeos, imagens que contribuem para a inserção da língua de sinais nos projetos desenvolvidos, dando maior autonomia para os alunos na resolução das atividades. Esses ajustes às especificidades e à diversidade humana permitem que a heterogeneidade seja compreendida como uma vantagem e não como um prejuízo.

Também se verificou que as atividades construídas permitiram que relações de mais alto nível de abstração reflexiva pudessem ser feitas pelos alunos, comprovando, dessa forma, que os materiais digitais podem ser um importante apoio no ensino da Matemática, desde que encontros significativos sejam proporcionados ao aluno com o objeto de estudo. Além disso, cabe destacar que os materiais, por si só, não desempenham as funções esperadas se não forem mediados por professores capacitados.

\section{REFERÊNCIAS}

ARNOLDO JUNIOR, H. Estudo do desenvolvimento do pensamento geométrico por alunos surdos por meio do Multiplano no ensino fundamental. Dissertação (Mestrado em Educação em Ciências e Matemática) - Pontifícia Universidade Católica do Rio Grande do Sul, PUCRS, 2010. 
BASTOS, F. P.; PEREIRA, V. L. B. Investigação-ação escolar: situação-problema na aprendizagem de conceitos matemáticos por alunos surdos. In: Espaço: informativo técnicocientífico do INES, Rio de Janeiro, n. 31, jan.-jun. 2009, p. 44-52.

BRASIL. Decreto $N^{o}$. 5.626, de 22 de dezembro de 2005. Brasília: Presidência da República - Casa Civil, 2005. Disponível em: <http://www.planalto.gov.br/ccivil_03/_Ato20042006/2005/Decreto/D5626.htm >. Acesso em: 14 de abril de 2011.

Ministério da Educação. Ensino Fundamental de nove anos: orientações para a inclusão da criança de seis anos de idade. Brasília: FNDE, Estação Gráfica, 2006.

CAPOVILLA, F. C. A evolução nas abordagens à educação da criança surda do oralismo à comunicação total, e desta ao bilinguismo. In: CAPOVILLA, F. C.; RAPHAEL, W. D. Dicionário enciclopédico ilustrado trilíngue: Língua Brasileira de Sinais. Volume II. $3^{\text {a }}$ Ed. São Paulo: Edusp, 2008, p. 1479-1940.

FAVERO, M. H.; PIMENTA, M. L. Pensamento e linguagem: a língua de sinais na resolução de problemas. Psicologia: reflexão e crítica, Porto Alegre, v. 19, 2006. Disponível em: http://scielo.br/prc. Acesso em janeiro de 2013.

GESSER, A. Libras? Que língua é essa? Crenças e preconceitos em torno da língua de sinais e da realidade surda. São Paulo: Afiliada, 2009.

GIL, A. C. Métodos e técnicas de pesquisa social. São Paulo: Atlas, 2008.

GOLDFELD, M. Linguagem e cognição numa perspectiva sociointeracionista. São Paulo: Plexus, 2002.

KAMII, C. A criança e o número. 32. ed. Campinas, SP: Papirus, 2004.

LOPES, M. C. Surdez e educação. Belo Horizonte: Autêntica, 2007.

LORENZATO, S. (Org.). O laboratório de ensino de matemática na formação de professores. Campinas: Autores Associados, 2006.

MACHADO, P. C. Diferença cultural e educação bilíngue: as narrativas dos professores surdos sobre questões curriculares. Florianópolis. Tese (Doutorado) - Universidade Federal de Santa Catarina, 2009.

MADALENA, S. P. A criança surda e a construção do conceito de número. Brasília: CORDE, 1997.

MARCONI, M. A.; LAKATOS, E. M. L. Fundamentos de metodologia científica. São Paulo: Atlas, 2007.

OLIVEIRA, J. S. A comunidade surda: perfil, barreiras e caminhos promissores no processo de ensino-aprendizagem em matemática. Rio de Janeiro: CEFET, 2005. Dissertação (Mestrado em Ensino de Ciências e Matemática), Centro Federal de Educação Tecnológica Celso Suckow da Fonseca, 2005.

QUADROS, R. M. Educação de surdos: a aquisição da linguagem. Porto Alegre: Artes Médicas, 1997. 
QUADROS, R. M.; CRUZ, C. R. Língua de sinais: instrumentos de avaliação. Porto Alegre: Artmed, 2011.

RODRIGUES, R. da S. Matemática na educação de surdos: investigando propostas de ensino nos anos iniciais do ensino fundamental. Dissertação (Mestrado) - ULBRA Universidade Luterana do Brasil, PPGECIM - Programa de Pós-Graduação em Ensino de Ciências e Matemática, Canoas, 2013.

ROSA, F. S. Literatura Surda: criação e produção de imagens e textos. Educação Temática Digital, Campinas, v.7, n.2, p.58-64, jun. 2006.

SALES, E. R. Refletir no silêncio: um estudo das aprendizagens na resolução de problemas aditivos com alunos surdos e pesquisadores ouvintes. Belém: 2008. Dissertação (Mestrado em Educação em Ciências e Matemática). Núcleo de Pesquisa e Desenvolvimento da Educação Matemática e Científica, Universidade Federal do Pará, 2008.

SANTANA, A. P. Surdez e linguagem: aspectos e implicações neurolinguísticas. São Paulo: Plexus, 2007.

SKLIAR, C. Uma análise preliminar das variáveis que intervém no projeto de educação bilíngue para os surdos. Revista Espaço, p. 49-57, 1997.

SKLIAR, C. A invenção e a exclusão da alteridade deficiente a partir dos significados da normalidade. Educação \& Realidade, Porto Alegre, v. 24, n. 2, p. 15-32, jul./dez. 1999.

SLOMSKI, V.G. Educação bilingue para surdos: concepções e implicações práticas. Curitiba: Juruá, 2010.

WEISS, A. M. L.; CRUZ, M. L. R. A informática e os problemas escolares de aprendizagem. 2. d. Rio de Janeiro: DP\&A, 1999. 